\title{
The effects of metabolite molecules produced by drinking water-isolated bacteria on their single and multispecies biofilms
}

\author{
Lúcia Chaves Simões $^{\mathrm{a} *}$, Manuel Simões ${ }^{\mathrm{b}}$ and Maria João Vieira ${ }^{\mathrm{a}}$ \\ ${ }^{a}$ IBB - Institute for Biotechnology and Bioengineering, Centre of Biological Engineering, University of Minho, Campus de Gualtar, \\ 4710-057 Braga, Portugal; ${ }^{b}$ LEPAE, Department of Chemical Engineering, Faculty of Engineering, University of Porto, Rua Dr \\ Roberto Frias, s/n, 4200-465 Porto, Portugal
}

(Received 22 February 2011; final version received 10 June 2011)

\begin{abstract}
The elucidation of the mechanisms by which diverse species survive and interact in drinking water (DW) biofilm communities may allow the identification of new biofilm control strategies. The purpose of the present study was to investigate the effects of metabolite molecules produced by bacteria isolated from DW on biofilm formation. Six opportunistic bacteria, viz. Acinetobacter calcoaceticus, Burkholderia cepacia, Methylobacterium sp., Mycobacterium mucogenicum, Sphingomonas capsulata and Staphylococcus sp. isolated from a drinking water distribution systems (DWDS) were used to form single and multispecies biofilms in the presence and absence of crude cell-free supernatants produced by the partner bacteria. Biofilms were characterized in terms of mass and metabolic activity. Additionally, several physiological aspects regulating interspecies interactions (sessile growth rates, antimicrobial activity of cell-free supernatants, and production of iron chelators) were studied to identify bacterial species with biocontrol potential in DWDS. Biofilms of Methylobacterium sp. had the highest growth rate and M. mucogenicum biofilms the lowest. Only B. cepacia was able to produce extracellular iron-chelating molecules. $A$. calcoaceticus, $B$. cepacia, Methylobacterium sp. and M. mucogenicum biofilms were strongly inhibited by crude cell-free supernatants from the other bacteria. The crude cell-free supernatants of M. mucogenicum and S. capsulata demonstrated a high potential for inhibiting the growth of counterpart biofilms. Multispecies biofilm formation was strongly inhibited in the absence of $A$. calcoaceticus. Only crude cell-free supernatants produced by B. cepacia and A. calcoaceticus had no inhibitory effects on multispecies biofilm formation, while metabolite molecules of $M$. mucogenicum showed the most significant biocontrol potential.
\end{abstract}

Keywords: drinking water bacteria; metabolite molecules; microbial interactions; single-species and multispecies biofilms

\section{Introduction}

Bacterial biofilms are complex communities of microorganisms embedded in a self-produced matrix and adhering to inert or living surfaces (Costerton et al. 1999). Biofilms have been observed on a variety of surfaces and in diverse niches, and are considered to be the prevailing microbial lifestyle in most environments (van Houdt et al. 2004). This sessile mode of life allows bacteria to enjoy a number of advantages over their planktonic counterparts, particularly the increased resistance to antimicrobial agents (Gilbert et al. 2002; Chorianopoulos et al. 2010; Ferreira et al. 2010; Simões et al. 2011).

The inner surfaces of drinking water (DW) pipes are invariably colonized by biofilms, regardless of the presence of a disinfectant residual. Biofilms on DW distribution systems (DWDS) may lead to a number of unwanted effects on the quality of the distributed water. In addition to the possibility of causing corrosion, turbidity, taste and odour problems, biofilms control the microbiological contents of the distributed water and are a potential source of pathogens (Percival and Walker 1999; Szewzyk et al. 2000; Manuel et al. 2009). Therefore, biofilm control is important for technical, aesthetic, regulatory and public health reasons.

DW networks can be regarded as biological reactors which host a wide variety of microorganisms, such as bacteria, protozoa and fungi (Amblard et al. 1996; Block et al. 1997). Microbial diversity leads to a variety of complex relationships involving interspecies and intraspecies interactions (Berry et al. 2006; Elenter et al. 2007; Hansen et al. 2007; Simões et al. 2007b). Interactions among bacterial species may have a profound influence on the initial stages of biofilm formation and development. Surface colonization by bacteria can enhance the attachment of other bacteria to the same surface. Some bacteria have an important role in biofilm onset by DW-isolated bacteria (Simões et al. 2007b, 2008a). Additionally, recent studies into

*Corresponding author. Email: luciachaves@deb.uminho.pt 
the microbial ecology of DWDS have found that microbial resistance to disinfectants is also affected by microbial community diversity and interspecies relationships (Berry et al. 2006; Simões et al. 2007c, 2010; 2011). The ecology of a biofilm is a complex function of the prevailing growth conditions, the hydrodynamic forces, the presence of microbial metabolites and molecules (cell-cell signalling communications) excreted by the microorganisms and the dominant microbial inhabitants of the biofilm (Banks and Bryers 1991; Bryers and Ratner 2004). The production and detection of bacterial cell-cell signalling molecules have been repeatedly linked to the enhanced development of single and multispecies biofilms (Irie and Parsek 2008).

Evidence of increased biofilm resistance to conventional disinfection treatments has led to the search for alternative control strategies. These include the use of interspecies interactions as biocontrol strategies (Gram et al. 1999; Mireles et al. 2001; Ammor et al. 2006), bacteriophages (Hughes et al. 1998; Tait et al. 2002; Sillankorva et al. 2004, 2010), enzymes (Meyer 2003; Olsen et al. 2007; Leroy et al. 2008; Lequette et al. 2010), quorum-sensing (QS) inhibitors (Rasmussen et al. 2005) and other compounds with the potential to interfere in biofilm formation such as iron chelators (Singh et al. 2002; Banin et al. 2005) and bacteriocinlike substances (Riley 1998; Messi et al. 2011). However, in order to develop new strategies for preventing biofilm formation, it is necessary to better understand the mechanisms by which different species survive and interact within a biofilm. Such biological mechanisms, alone or as part of synergistic procedures, could provide a new line of efficient biofilm control strategies.

The aim of this study was to understand the effects of metabolite molecules produced by bacteria isolated from DW on single and multispecies biofilm formation and development and to evaluate their potential as a biocontrol strategy. With this purpose, bacterial aspects regulating interspecies interactions (sessile growth rates, the antimicrobial activity of crude cellfree supernatants, and the production of iron chelators) were characterized with the aim of identifying bacterial species with biocontrol potential in DWDS. Furthermore, the effects of crude cell-free supernatants of DW bacteria were studied on single and multispecies biofilm formation by the partner bacteria.

\section{Materials and methods}

\section{Isolation and identification of bacteria}

The bacteria used throughout this work were isolated from a model laboratory DWDS, as described previously by Simões et al. (2006). Identification tests, by determination of $16 \mathrm{~S}$ rDNA gene sequence, were performed according to the method described by Simões et al. (2007a). The assays were performed with six representative DW-isolated bacteria, viz. Acinetobacter calcoaceticus, Burkholderia cepacia, Methylobacterium sp., Mycobacterium mucogenicum, Sphingomonas capsulata and Staphylococcus sp., respectively. The bacterial genera used in this study represented $>80 \%$ of the total genera isolated and identified (results not shown).

\section{Planktonic bacterial cell growth}

Bacterial cells were grown overnight in batch culture using $100 \mathrm{ml}$ of R2A (Merck, Portugal) broth, at room temperature $\left(23 \pm 2^{\circ} \mathrm{C}\right)$, under agitation $(150 \mathrm{rpm})$. Cells were harvested by centrifugation $(20 \mathrm{~min}$ at $13,000 \mathrm{~g}, 4^{\circ} \mathrm{C}$ ), washed three times in $0.1 \mathrm{M}$ saline phosphate buffer (0.1 M PBS, pH 7.2) and resuspended in the volume of R2A broth necessary to achieve a cellular density of $1 \times 10^{8}$ cells $\mathrm{ml}^{-1}$ (Simões et al. 2007b).

To obtain the cell-free supernatants, the bacteria were inoculated in $100 \mathrm{ml}$ of R2A broth, and allowed to grow for 10 days, to stabilize the growth phase (Andersson et al. 1998), at room temperature and under agitation. Following the incubation period, cell suspensions were centrifuged $\left(20 \mathrm{~min}\right.$ at $13,000 \mathrm{~g}, 4^{\circ} \mathrm{C}$ ) and the supernatants were filter-sterilized using $0.2 \mu \mathrm{m}$ filters (Orange Scientific, USA). Subsequently, the crude cell-free supernatants were stored at $-4^{\circ} \mathrm{C}$.

\section{Sessile growth rate determination}

The growth rates of sessile DW-isolated bacteria were determined by monitoring their biofilm growth using 96-well microtiter plates according to the modified microtiter plate test proposed by Stepanović et al. (2000), using R2A broth as the growth medium. To promote bacterial sessile growth over time, the microtiter plates were incubated aerobically on an orbital shaker, at $150 \mathrm{rpm}$ and room temperature. The biofilm cell density over time was assessed by the standard plate count method using R2A agar as the culture medium (Reasoner and Geldrich 1985; Simões et al. 2006). The biofilm in each well of the microtiter plates was scraped with a sterile scalpel into $200 \mu \mathrm{l}$ of sterile sodium phosphate buffer $(0.2 \mathrm{M} ; \mathrm{pH}$ 7). Before serial dilution, biofilm suspensions were vortexed for $2 \mathrm{~min}$ and then used to assess colony forming units (CFUs). CFUs were counted after incubation for 7-15 days at room temperature to allow the enumeration of slow-growing bacteria adapted to oligotrophic conditions. The experiments were performed in triplicate with three repeats. 


\section{Assay of antimicrobial activity}

To assess the potential antimicrobial activity of crude cell-free supernatants, these were inoculated onto lawns of the other bacteria grown overnight in R2A broth, at room temperature and under agitation. The other bacteria were spread $(100 \mu \mathrm{l})$ onto R2A agar and airdried for $30 \mathrm{~min}$. Then $10 \mu \mathrm{l}$ of crude cell-free supernatant were directly applied onto the lawns and left to dry, as described by Kolari et al. (2001). Afterwards, the plates were incubated at room temperature for 3-5 days and subsequently the presence of inhibitory halos was evaluated. Sterile R2A broth was used as a negative control and sodium hypochlorite at $10 \mathrm{mg}^{-1}$ as a positive control (Simões et al. 2010).

\section{Production of iron chelators}

The screening for iron chelator production was assayed on chrome azurol S (CAS) agar, based on the methodology described by Schwyn and Neilands (1987). A positive result was indicated by the colour change of the CAS agar from dark blue to bright yellow. In liquid medium, those molecules were detected by the CAS assay (Schwyn and Neilands 1987). Equal volumes of cell-free supernatants and CAS assay solution were mixed and left for $30 \mathrm{~min}$ at room temperature. The absorbance at $630 \mathrm{~nm}$ (BIOTEK, Synergy HT, Vermont, USA) was measured with sterile medium and CAS assay solution as blanks. A negative value indicated the presence of iron-chelating molecules, such as siderophores.

\section{Single and multispecies biofilm formation with and without crude cell-free supernatants}

Single and multispecies biofilms were developed according to the modified microtiter plate test proposed by Stepanović et al. (2000) using R2A broth as growth medium. Single species biofilm formation was performed with the six isolated bacteria and with the bacteria plus crude cell-free supernatants of other different bacteria. Multispecies biofilms were developed with seven different bacterial combinations, viz. one mixture of all six bacteria and six combinations with a mixture of five distinct bacteria, through a strain exclusion process (biofilm formation in the absence of a specific strain or replacing the specific strain by its crude cell-free supernatant, obtaining distinct species combinations) (Simões et al. 2008a). For each condition the wells of sterile 96-well flat tissue culture plates (polystyrene, Orange Scientific, USA) were filled under aseptic conditions with $180 \mu$ l of a cell suspension and $20 \mu \mathrm{l}$ of cell-free supernatant resulting in a final

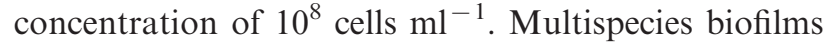
were developed with equal initial cell densities of each isolate. To promote biofilm formation, plates were incubated aerobically on an orbital shaker, at $150 \mathrm{rpm}$ and room temperature, for 24,48 and $72 \mathrm{~h}$. The growth media plus crude cell-free supernatants were carefully discarded and freshly added every $24 \mathrm{~h}$. All experiments were performed in triplicate with at least three repeats. Negative controls were obtained by incubating the wells with R2A broth without adding any bacterial cells. After each biofilm formation period, the content of each well was removed and the wells were washed three times with $250 \mu \mathrm{l}$ of sterile distilled water to remove reversibly adherent bacteria. Afterwards, the biofilms were analysed in terms of biomass adhered and metabolic activity.

\section{Biomass quantification by $\mathrm{CV}$}

The biomass adhered to the inner walls of the wells was quantified by the crystal violet $(\mathrm{CV})$ method according to the procedure described by Simões et al. (2007b). Biofilm mass results are presented as relative percentages according to the following expressions:

For single species biofilms:

Relative biofilm mass $(\%)=$

$\frac{\mathrm{OD}_{570 \mathrm{~nm}} \text { of biofilms with crude cell }- \text { free supernatant }}{\mathrm{OD}_{570 \mathrm{~nm}} \text { of biofilms without crude cell }- \text { free supernatant }}$ $\times 100$

For multispecies biofilms:

Relative biofilm mass $(\%)=$

$$
\frac{\mathrm{OD}_{570 \mathrm{~nm}} \text { of biofilms with strain exclusion }}{\mathrm{OD}_{570 \mathrm{~nm}} \text { of biofilms with all six bacteria }} \times 100
$$

\section{Respiratory activity assessment by XTT}

Bacterial metabolic activity was determined using the sodium 3,3'-[1[(phenylamino)carbonyl]- 3,4-tetrazolium]-bis(4-methoxy-6-nitro) benzene sulfonic acid hydrate (XTT) colorimetric method according to the procedure described by Simões et al. (2007b). The specific respiratory activity of the biofilm was presented as $\mathrm{OD}_{490 \mathrm{~nm}} / 570 \mathrm{~nm}$ (biofilm respiratory activity/ biofilm mass), based on Simões et al. (2007b) and the results are presented as relative percentages according to the following expressions:

For single species biofilms:

$$
\begin{aligned}
& \text { Relative specific biofilm activity }(\%)= \\
& \mathrm{OD} \frac{490 \mathrm{~nm}}{570 \mathrm{~nm}} \text { of biofilms with crude cell }- \text { free supernatant } \\
& \mathrm{OD}_{\frac{490 \mathrm{~nm}}{570 \mathrm{~mm}}} \text { of biofilms without crude cell }- \text { free supernatant } \\
& \times 100
\end{aligned}
$$


For multispecies biofilms:

$$
\begin{aligned}
& \text { Relative specific biofilm activity }(\%)= \\
& \frac{\mathrm{OD} \frac{490 \mathrm{~nm}}{570 \mathrm{~nm}} \text { of biofilms with strain exclusion }}{\mathrm{OD}_{\frac{490 \mathrm{~m}}{50 \mathrm{~mm}}} \text { of biofilms with all six bacteria }} \times 100
\end{aligned}
$$

\section{Biofilm classification and statistical analysis}

In order to better understand the effects of crude cellfree supernatants on single- and multispecies biofilms the relative percentage values of mass or activity for each biofilm ( $\%$ B) were compared with the relative percentage values of biofilm mass and activity for the control experiment $\left(\% \mathrm{~B}_{\mathrm{C}}\right)$. For the single species biofilms, $B_{C}$ is the biofilm without crude cell-free supernatant, while for multispecies biofilms this is the scenario with all six bacteria. The biofilms were classified as follows: strongly inhibited $(--)$ : $\% \mathrm{~B}$ $\leq \mathrm{Bc} / 2(\%)$; weakly inhibited (-): $\mathrm{Bc} / 2(\%)<\%$ $\mathrm{B}<\mathrm{Bc}(\%)$; strongly improved $(++): \% \mathrm{~B} \geq 2 \mathrm{Bc}$ $(\%)$; weakly improved $(+)$ : $\mathrm{Bc}(\%)<\% \mathrm{~B}<2 \mathrm{Bc}(\%)$. The average value of the relative percentage of biofilm mass or activity for the three sampling times was used to determine the classification.

The data were analysed using the statistical program SPSS version 17.0 (Statistical Package for the Social Sciences). The mean and standard deviation (SD) within samples were calculated for all cases. The data were analyzed by the nonparametric Wilcoxon test based on a confidence level of $\geq 95 \% \quad(P<0.05$ was considered statistically significant).

\section{Results}

\section{Biofilm growth rates}

Biofilm growth was performed with the DW-isolated bacteria to assess growth rates in R2A broth (Table 1). Methylobacterium sp. biofilms had the highest growth rate and $M$. mucogenicum biofilms the lowest $(P<0.05)$. S. capsulata and Staphylococcus sp. biofilms had similar growth rates $(P>0.05)$, which were

Table 1. Biofilm growth rates.

\begin{tabular}{lc}
\hline & Growth rates $\left(\mathrm{h}^{-1}\right)$ \\
\cline { 2 - 2 } Bacteria & Biofilm \\
\hline A. calcoaceticus & $0.745 \pm 0.057$ \\
B. cepacia & $0.772 \pm 0.018$ \\
Methylobacterium sp. & $1.003 \pm 0.035$ \\
M. mucogenicum & $0.623 \pm 0.070$ \\
S. capsulata & $0.851 \pm 0.020$ \\
Staphylococcus $\mathrm{sp}$. & $0.903 \pm 0.085$ \\
\hline
\end{tabular}

Note: The means \pm SDs are presented. significantly higher than those observed for A. calcoaceticus and $B$. cepacia biofilms $(P<0.05)$.

\section{Antimicrobial activity and production of iron chelators}

Planktonic studies were performed with the DWisolated bacteria to assess the antimicrobial activity of crude cell-free supernatants, and the production of iron chelators (Table 2). The assays of the antimicrobial activity with all the supernatants showed no effects on bacterial growth and only B. cepacia and Methylobacterium sp. produced iron-chelating molecules, such as siderophores. However, only B. cepacia was able to produce extracellular iron-chelating molecules.

\section{Single species biofilm formation with and without crude cell-free supernatants}

In order to investigate the effects of crude cell-free supernatants of each bacterium on single species biofilm formation and specific respiratory activity of the several DW-isolated bacteria, the standard 96-well microtiter plate technique was used with $\mathrm{CV}$ and XTT staining. To better understand the function of crude cell-free supernatants in single species biofilm formation, the relative percentages of biofilm mass (Figure 1) and specific respiratory activity (Figure 2) were calculated over time and compared with each single species biofilm. Additionally, the single species biofilms were classified as strongly/weakly inhibited or strongly/weakly improved by the presence of crude cell-free supernatants (Table 3 ).

In general, there was an inversely proportional relationship of time-biomass formation for the several single species biofilms with crude cell-free supernatants (Figure 1). A. calcoaceticus (Figure 1A), B. cepacia (Figure 1B), Methylobacterium sp. (Figure 1C) and $M$. mucogenicum (Figure 1D) biofilms were inhibited by the cell-free supernatants from the partner bacteria. Their biomass was lower than for single species biofilms

Table 2. Screening for antimicrobial activity and iron chelator production by DW-isolated bacteria.

\begin{tabular}{lccc}
\hline & & \multicolumn{2}{c}{ Iron chelators } \\
\cline { 3 - 4 } Bacteria & $\begin{array}{l}\text { Antimicrobial } \\
\text { activity }\end{array}$ & $\begin{array}{l}\text { CAS } \\
\text { agar }\end{array}$ & $\begin{array}{c}\text { CAS } \\
\text { assay }\end{array}$ \\
\hline A. calcoaceticus & - & - & - \\
B. cepacia & - & + & + \\
Methylobacterium sp. & - & + & - \\
M. mucogenicum & - & - & - \\
S. capsulata & - & - & - \\
Staphylococcus $\mathrm{sp}$. & - & - & - \\
\hline
\end{tabular}

Note: $-=$ not detected; $+=$ detected. 
A

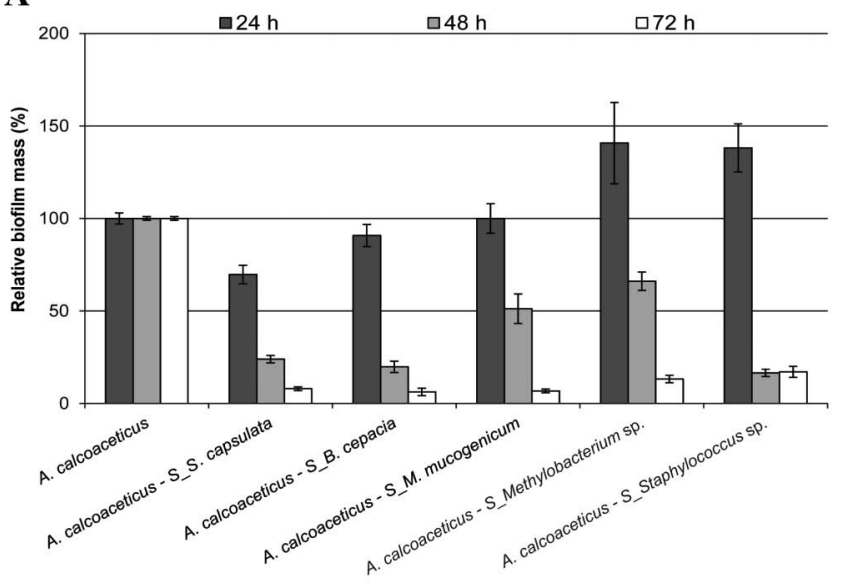

C

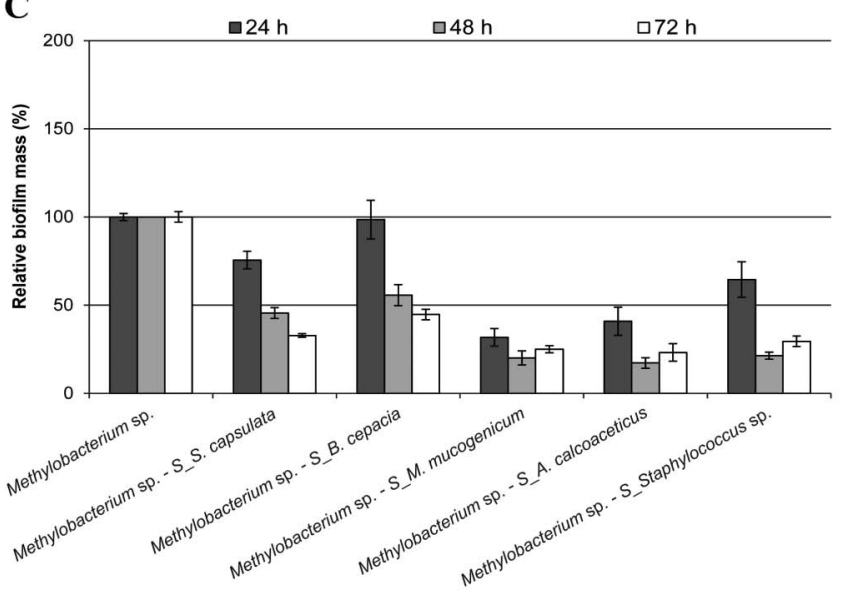

$\mathbf{E}$

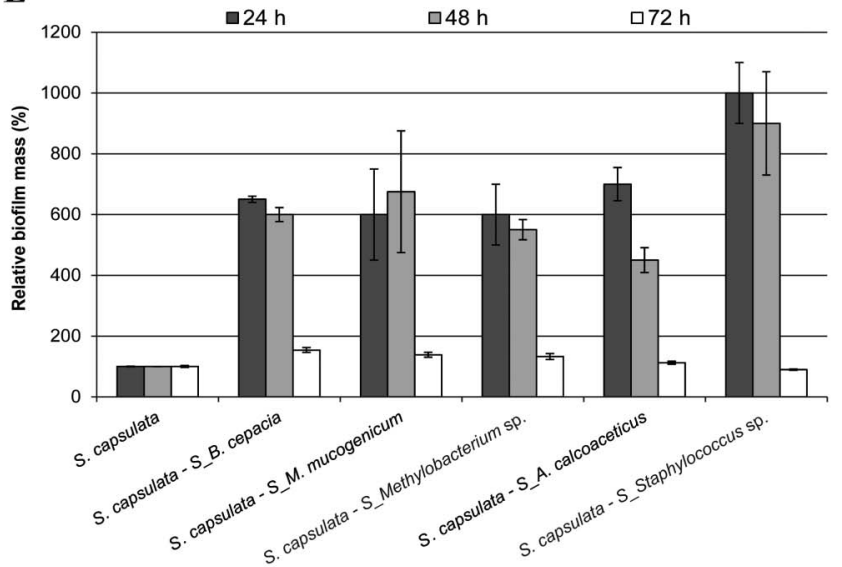

B

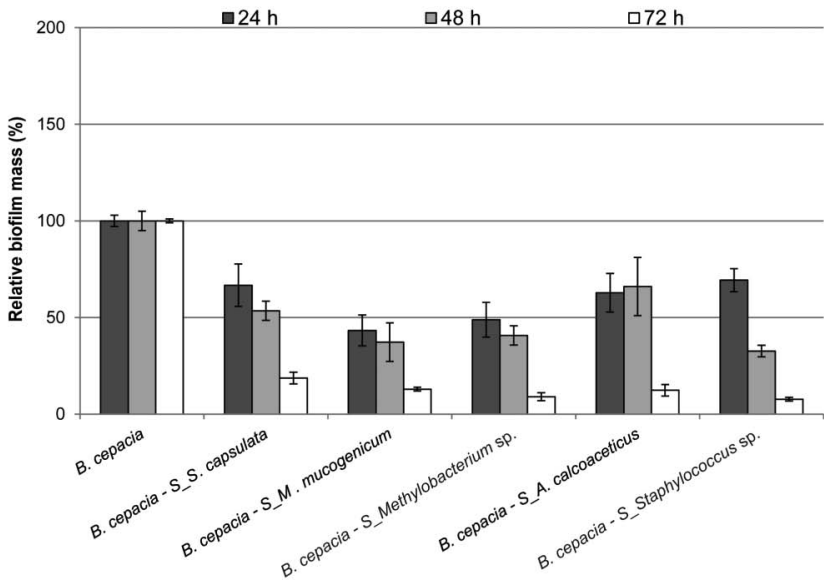

D

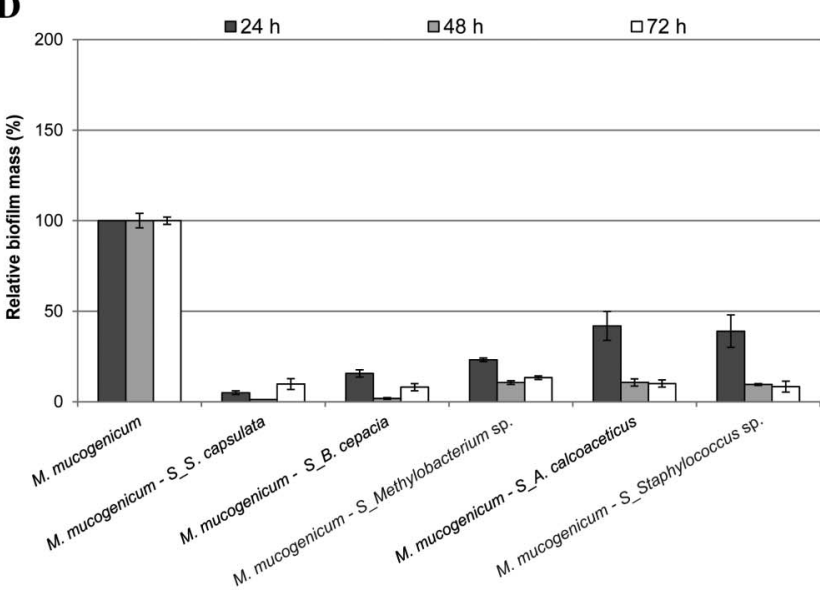

$\mathbf{F}$

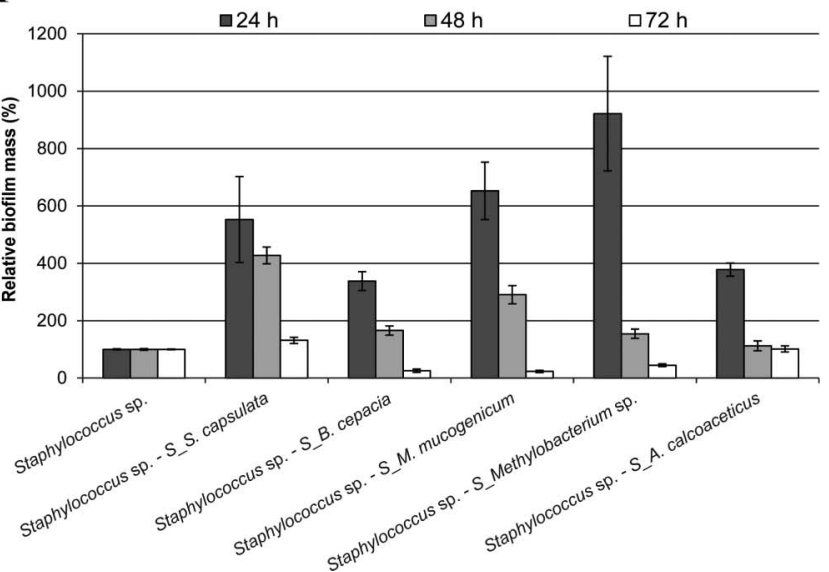

Figure 1. Relative percentage of mass for A. calcoaceticus (A), B. cepacia (B), Methylobacterium sp. (C), M. mucogenicum (D), S. capsulata (E) and Staphylococcus sp. (F) single species biofilms with crude cell-free supernatants from the partner DW bacteria, after biofilm formation for 24,48 and $72 \mathrm{~h}$. The means \pm SDs for at least three replicates are illustrated.

without cell-free supernatants $(P<0.05)$, with the exception of $A$. calcoaceticus biofilms $(24 \mathrm{~h})$ with Methylobacterium sp. and Staphylococcus sp. cell-free supernatants. M. mucogenicum single biofilms were the most affected by the crude cell-free supernatants from the other bacteria, followed by $B$. cepacia and Methylobacterium biofilms $(P<0.05)$. A. calcoaceticus biofilms were the least affected $(P<0.05)$. On the 
A

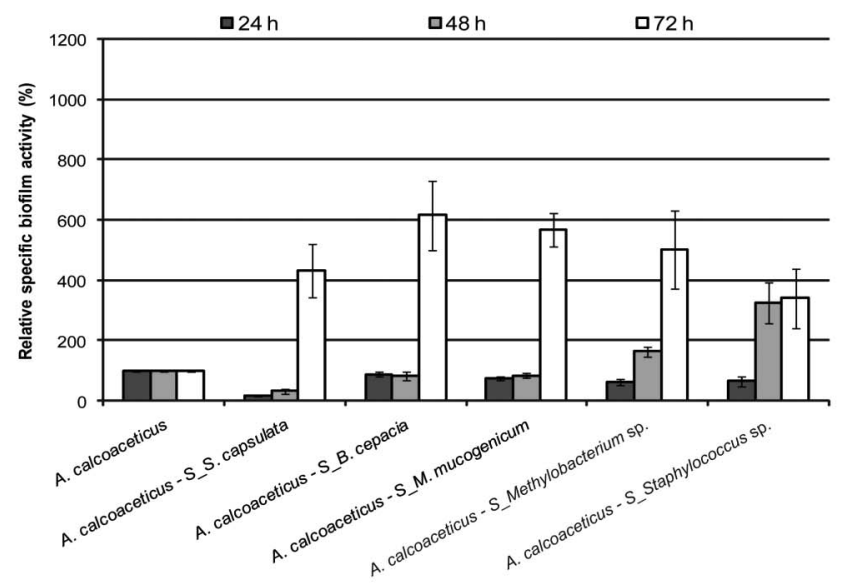

C

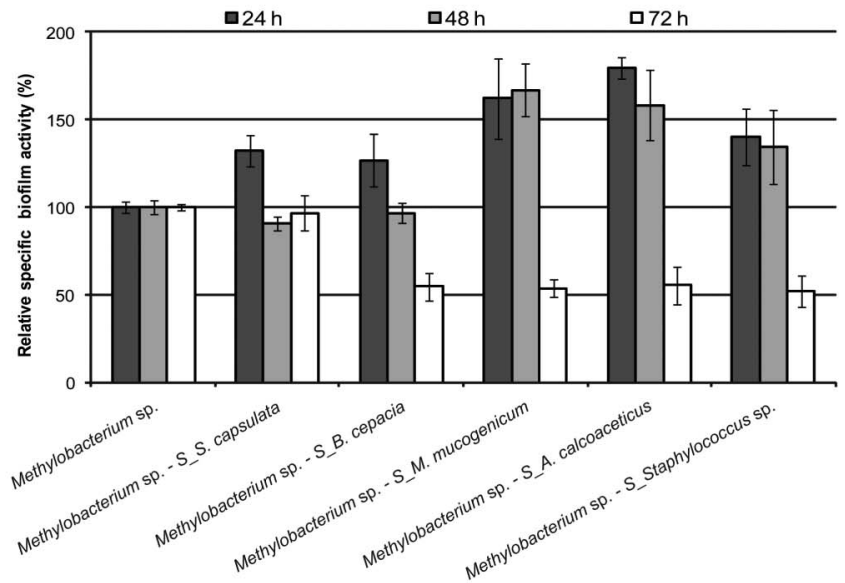

$\mathbf{E}$

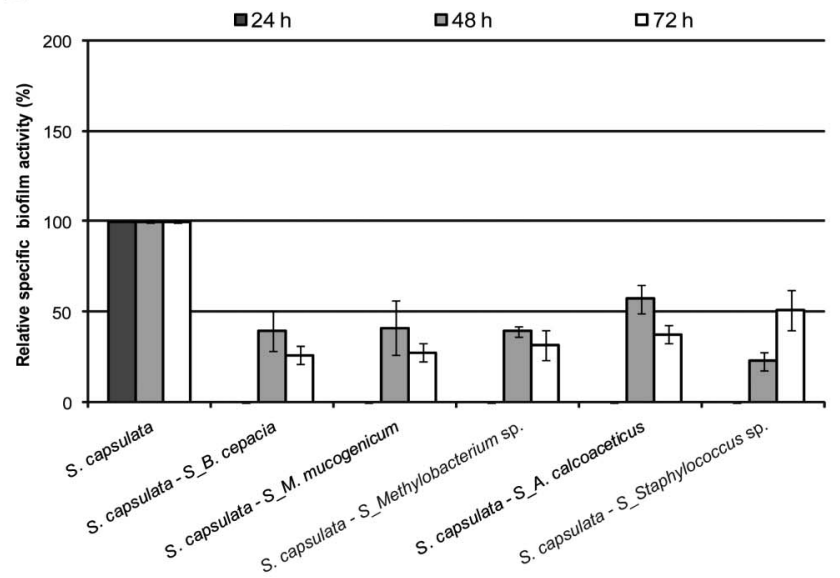

B

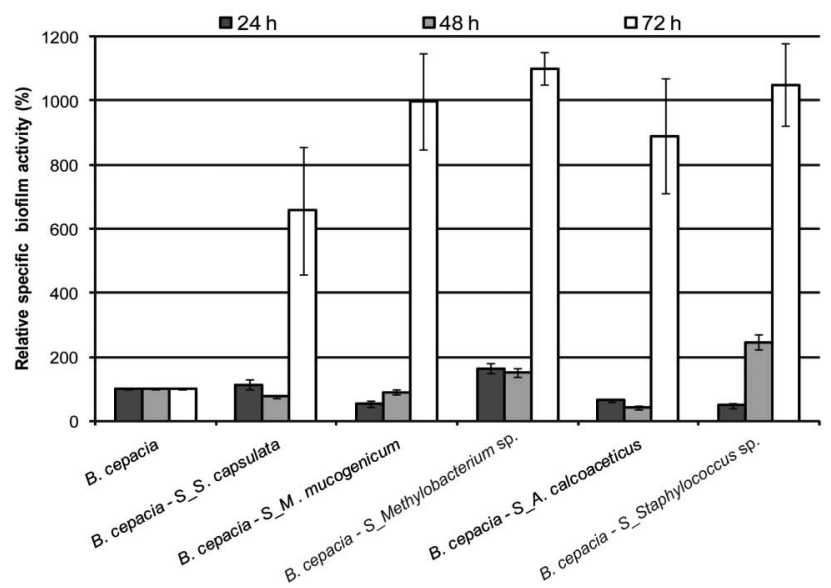

D

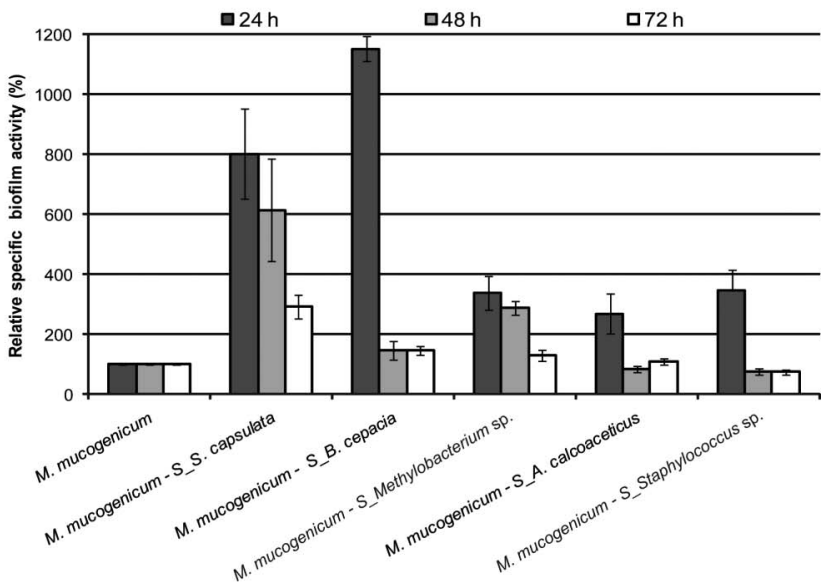

$\mathbf{F}$

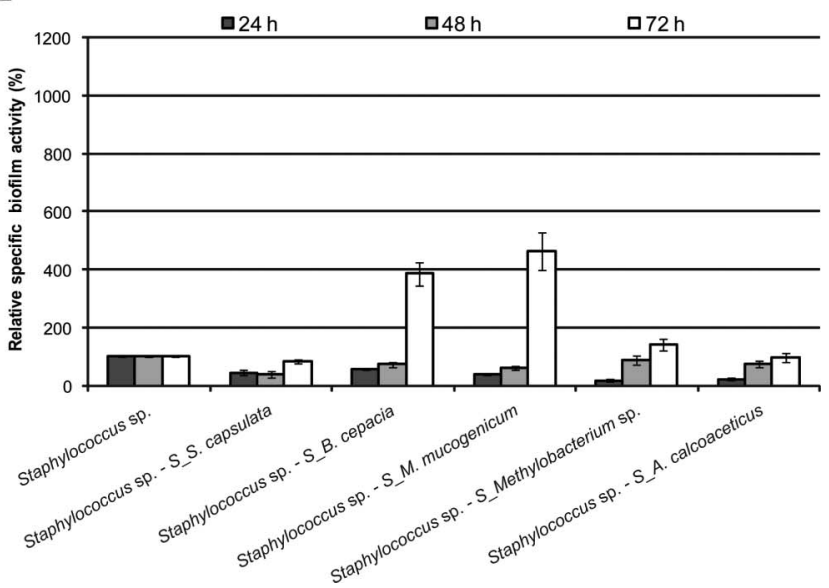

Figure 2. Relative percentage of specific activity for A. calcoaceticus (A), B. cepacia (B), Methylobacterium sp. (C), M. mucogenicum (D), S. capsulata (E) and Staphylococcus sp. (F) single species biofilms with crude cell-free supernatants from the partner DW bacteria, after biofilm formation for 24,48 and $72 \mathrm{~h}$. The means \pm SDs for at least three replicates are illustrated.

other hand, S. capsulata (Figure 1E) and Staphylococcus sp. (Figure 1F) biofilms increased in the presence of cell-free supernatants from the other bacteria $(P<0.05)$. Their biofilm mass was higher $(P<0.05)$ than single species biofilms without crude cell-free supernatants, with the exception of $S$. capsulata biofilms (72 h) with Staphylococcus sp. cell-free supernatant, Staphylococcus sp. biofilms $(72$ h) with 
Table 3. Effects of cell-free supernatants on mass and metabolic activity of single species biofilms of DW-isolated bacteria.

\begin{tabular}{|c|c|c|c|c|c|c|c|c|c|c|c|c|}
\hline \multirow{3}{*}{$\begin{array}{l}\text { Single species } \\
\text { biofilms }\end{array}$} & \multicolumn{12}{|c|}{ Cell-free supernatants } \\
\hline & \multicolumn{2}{|c|}{$\begin{array}{c}\text { A. } \\
\text { calcoaceticus }\end{array}$} & \multicolumn{2}{|c|}{ B. cepacia } & \multicolumn{2}{|c|}{$\begin{array}{l}\text { Methylobacterium } \\
\text { sp. }\end{array}$} & \multicolumn{2}{|c|}{$\begin{array}{c}M . \\
\text { mucogenicum }\end{array}$} & \multicolumn{2}{|c|}{ S. capsulata } & \multicolumn{2}{|c|}{$\begin{array}{c}\text { Staphylococcus } \\
\text { sp. }\end{array}$} \\
\hline & Mass & Activity & Mass & Activity & Mass & Activity & Mass & Activity & Mass & Activity & Mass & Activity \\
\hline A. calcoaceticus & & & -- & ++ & - & ++ & - & ++ & -- & + & - & ++ \\
\hline B. серасіа & -- & ++ & & & -- & ++ & -- & ++ & -- & ++ & -- & ++ \\
\hline Methylobacterium sp. & -- & + & - & - & & & -- & + & - & + & -- & + \\
\hline M. mисовепicum & -- & + & -- & ++ & -- & ++ & & & -- & ++ & -- & + \\
\hline S. capsulata & ++ & -- & ++ & -- & ++ & -- & ++ & -- & & & ++ & -- \\
\hline Staphylococcus sp. & + & - & + & + & ++ & - & ++ & + & ++ & - & & \\
\hline
\end{tabular}

Note: $--=$ strong biofilm inhibition; $-=$ weak biofilm inhibition; $++=$ strong biofilm increase; $+=$ weak biofilm increase.

B. cepacia, M. mucogenicum and Methylobacterium sp. cell-free supernatants. S. capsulata (Figure 1E) single biofilms had the highest biomass increase $(P<0.05)$ in the presence of crude cell-free supernatants from the other bacteria.

Concerning the percentage of specific respiratory activity (Figure 2) there was a general decrease over time for Methylobacterium sp. and M. mucogenicum single species biofilms in the presence of cell-free supernatants. However, the values were mostly higher than in the control experiments $(P<0.05)$. The other bacteria (A. calcoaceticus, B. cepacia, S. capsulata and Staphylococcus sp.) formed single biofilms in the presence of cell-free supernatants with a general increase in metabolic activity over time $(P<0.05)$. $S$. capsulata (Figure $2 \mathrm{E}$ ) was the only single species biofilm where activity was significantly inhibited by the cell-free supernatants from the different bacteria when compared with the control experiments $(P<0.05)$. The other single biofilms showed variable behavior in the presence of cell-free supernatants. Single biofilms of Staphylococcus sp. were the subsequent biofilms most $(P<0.05)$ affected by the presence of cell-free supernatants, followed by single biofilms of Methylobacterium sp. Single biofilms of $B$. cepacia and $A$. calcoaceticus were affected to a lower extent and $M$. mucogenicum biofilms were the least $(P>0.05)$ affected by the presence of crude cell-free supernatants from other bacteria.

Comparing the percentage of relative biofilm mass and specific activity (Figures 1 and 2) for each single species biofilms, those biofilms most affected by cellfree supernatants in terms of mass were the least affected in terms of metabolic activity. For instance, $M$. mucogenicum single biofilms were the most inhibited in terms of mass by the cell-free supernatants from the other bacteria $(P<0.05)$. However, these biofilms were the most metabolically actives, ie the cellfree supernatants potentiated biofilm activity
$(P<0.05)$. This finding was verified by the results for classification of single species biofilms (Table 3). There were contradictory findings between the mass and specific metabolic activity for all the single species biofilms, except for single species biofilms of Methylobacterium sp. with B. cepacia cell-free supernatant, and Staphylococcus sp. biofilms with B. cepacia and $M$. mucogenicum cell-free supernatants. For these biofilms, the presence of crude cell-free supernatant lead to a simultaneous decrease or increase in biofilm formation and specific metabolic activity, respectively. Crude cellfree supernatants inhibited biofilm formation in all single species biofilms, except those of $S$. capsulata and Staphylococcus sp. All cell-free supernatants caused a strong increase in the mass of $S$. capsulata biofilms. For biofilms of Staphylococcus sp., crude cell-free supernatants of $A$. calcoaceticus and B. cepacia only led to a weak increase in biofilm mass, and the other supernatants led to a strong increase in biofilm formation. The biofilms inhibited by cell-free supernatants were for the most part strongly inhibited. $B$. cepacia and $M$. mucogenicum biofilms were the most affected by crude cell-free supernatants (strongly inhibited for all the situations), while Methylobacterium sp. and $A$ calcoaceticus biofilms were the least affected.

\section{Multispecies biofilm formation with and without crude cell-free supernatants}

To better understand the function of each bacterium and/or their metabolites on multispecies biofilm formation, the relative percentage of biofilm (mass and activity) was calculated for multispecies biofilm with and without cell-free supernatants (Figure 3). Moreover, similar to the single species biofilms and with the purpose of better understanding the effects of each crude cell-free supernatant/bacterium on multispecies biofilm mass and specific metabolic activity, biofilms were classified as strongly/weakly inhibited or 
A

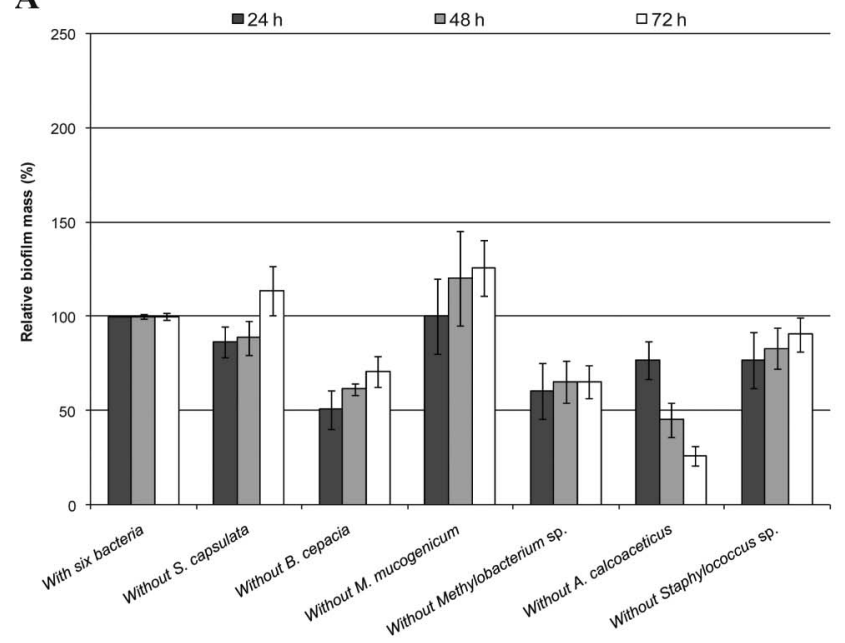

C

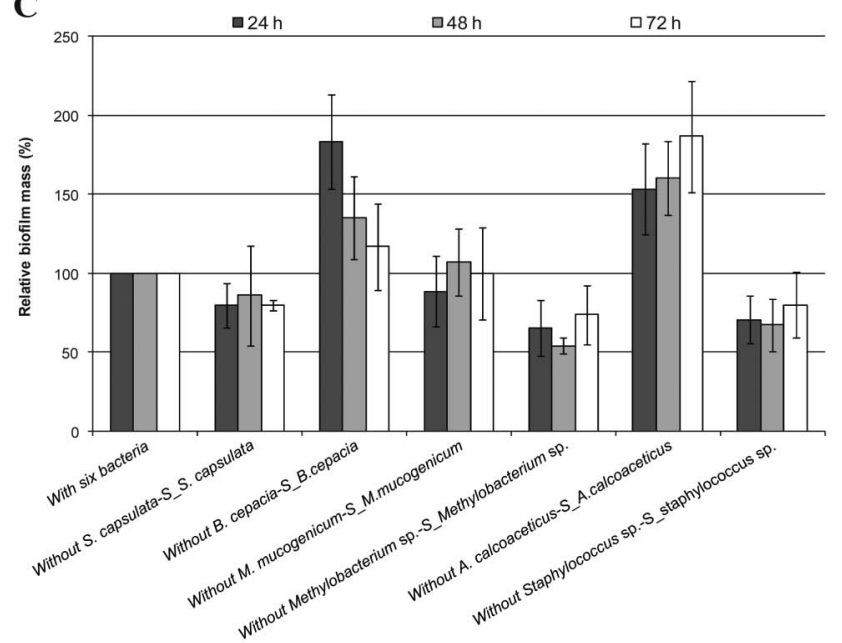

B

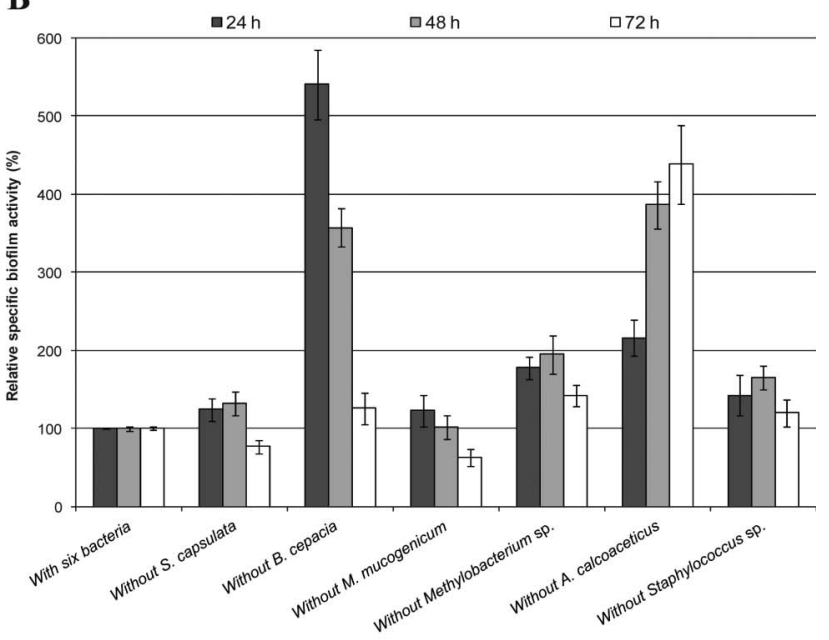

D

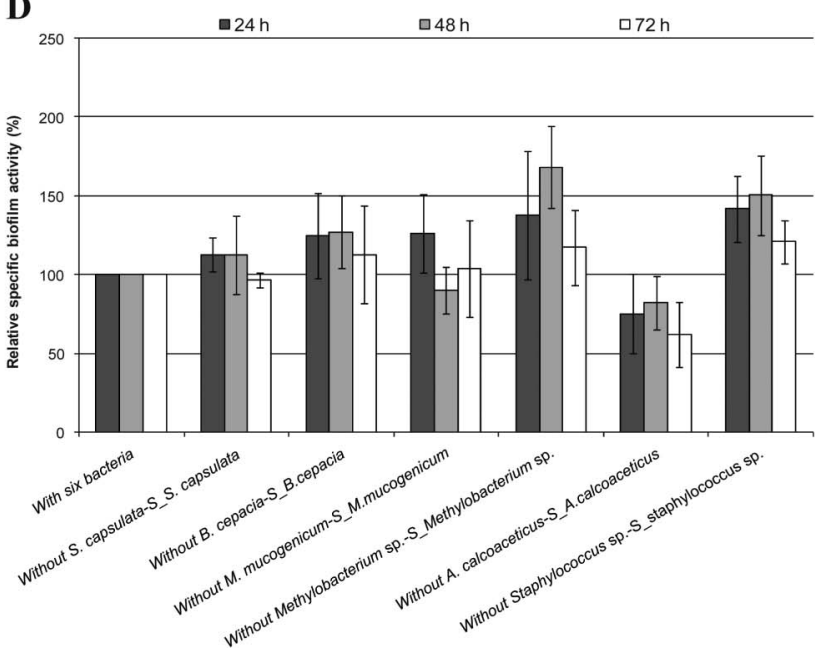

Figure 3. Relative percentage of mass (A and C) or specific metabolic activity (B and D) for multispecies biofilms with (C and D) and without (A and B) crude cell-free supernatants from the partner DW bacteria, after biofilm formation for 24, 48 and $72 \mathrm{~h}$. The means \pm SDs for at least three replicates are illustrated.

strongly/weakly improved by the presence of cell-free supernatants or the absence of one specific bacterium (Table 4).

The mass of multispecies biofilms without cell-free supernatants increased over time for all situations $(P<0.05)$, except for multispecies biofilms without A. calcoaceticus (Figure 3A). M. mucogenicum was the only species that, when absent, resulted in a relative increase $(P<0.05)$ in biofilm mass over time compared to biofilm formation with all six bacteria. The remaining bacteria reduced biofilm formation. The decrease in mass formation was less significant $(P>0.05)$ for biofilms in the absence of $S$. capsulata (24 and $48 \mathrm{~h}$ ) and Staphylococcus sp. (72 h), and more significant $(P<0.05)$ in the absence of $B$. cepacia $(24$ h) and A. calcoaceticus (48 and $72 \mathrm{~h}$ ). Nevertheless, even if the relative biofilm formation decreased for five of the six strain exclusion scenarios, it was only significant $(P<0.05)$ and decreased over time $(P<0.05)$ for biofilms without A. calcoaceticus. Biofilms in the absence of $A$. calcoaceticus were strongly inhibited, the other biofilms were weakly inhibited, except multispecies biofilms without $M$. mucogenicum which were weakly improved (Table 4).

All six strain exclusion scenarios increased biofilm activity (Figure 3B) compared to multispecies biofilms with all the six bacteria, except for those biofilms without $S$. capsulata and M. mucogenicum $(72 \mathrm{~h})$. The decrease in activity was only significant $(P<0.05)$ for biofilms in the absence of $M$. mucogenicum (Table 4). The increase in biofilm activity was less significant $(P>0.05)$ for biofilms in the absence of $M$. 
Table 4. Effects of cell-free supernatants on the mass and metabolic activity of multispecies biofilms of DW-isolated bacteria.

\begin{tabular}{|c|c|c|c|c|}
\hline \multirow{3}{*}{$\begin{array}{l}\text { Multispecies } \\
\text { biofilms }\end{array}$} & \multicolumn{4}{|c|}{ Cell-free supernatants } \\
\hline & \multicolumn{2}{|c|}{ Without } & \multicolumn{2}{|c|}{ With } \\
\hline & Mass & Activity & Mass & Activity \\
\hline \multicolumn{5}{|l|}{ Without } \\
\hline S. capsulata & - & + & - & + \\
\hline B. серасіа & - & ++ & + & + \\
\hline М. тисовепісит & + & - & - & + \\
\hline Methylobacterium sp. & - & + & - & + \\
\hline A. calcoaceticus & -- & ++ & + & - \\
\hline Staphylococcus sp. & - & + & - & + \\
\hline
\end{tabular}

Note: $--=$ strong biofilm inhibition; $-=$ weak biofilm inhibition; $++=$ strong biofilm increase; $+=$ weak biofilm increase.

mucogenicum (24 and $48 \mathrm{~h}$ ) and Staphylococcus sp. (72 h), and more significant $(P<0.05)$ in the absence of $B$. cepacia $(24 \mathrm{~h})$ and $A$. calcoaceticus (48 and $72 \mathrm{~h}$ ). However, even when the relative biofilm activity increased for all strain exclusion scenarios, it was only significant $(P<0.05)$ and increased over time for biofilms without $A$. calcoaceticus $(P<0.05)$. Biofilm classification (in terms of activity) showed that the majority of biofilms were strongly (without $B$. cepacia and A. calcoaceticus) or weakly (without $S$. capsulata, Methylobacterium sp. and Staphylococcus sp.) improved (Table 4). The biofilms without M. mucogenicum were weakly inhibited.

Analysing the multispecies biofilms with crude cellfree supernatants (Figure 3C), biofilm mass tended to increase over time, except for biofilms with $B$. cepacia cell-free supernatants. Multispecies biofilms with cellfree supernatants of B. cepacia, A. calcoaceticus and M. mucogenicum (48 and $72 \mathrm{~h}$ ) lead to a relative increase in biofilm mass compared to biofilm formation with the six bacteria. The other cell-free supernatants reduced biofilm mass. The decrease in biofilm mass formation was less significant $(P>0.05)$ for biofilms with cell-free supernatants of $M$. mucogenicum (24 h), S. capsulata (48h) and Staphylococcus sp. (72 h), and more significant $(P<0.05)$ with Methylobacterium sp. cell-free supernatants $(24,48$, and $72 \mathrm{~h})$. On the other hand, the increase in biomass was less significant $(P>0.05)$ for biofilms with cell-free supernatants of A. calcoaceticus ( $24 \mathrm{~h}$ ) and M. mucogenicum (48 and 72 h), and more significant $(P<0.05)$ in the presence of B. cepacia $(24 \mathrm{~h})$ and A. calcoaceticus $(48$ and $72 \mathrm{~h})$ cell-free supernatants. Multispecies biofilms with cellfree supernatants were weakly inhibited for most of the situations, except for biofilms with $B$. cepacia and A. calcoaceticus cell-free supernatants (weakly improved) (Table 4).
The results of the metabolic activity of multispecies biofilms with crude cell-free supernatants (Figure 3D) showed that in five of the six strain exclusion scenarios increased activity (considering the average values of three sampling times). Only in multispecies biofilms in the presence of A. calcoaceticus cell-free supernatants was there reduced biofilm activity over time compared to the multispecies biofilms with all six bacteria. The increase in biofilm activity was less significant $(P>0.05)$ for biofilms with the cell-free supernatants of S. capsulata (24 and $48 \mathrm{~h}$ ) and M. mucogenicum (72 $\mathrm{h})$, and more significant $(P<0.05)$ in the presence of Staphylococcus sp. (24 and $72 \mathrm{~h}$ ) and Methylobacterium sp. (48 h) cell-free supernatants. Biofilm activity data showed that the presence of all cell-free supernatants weakly improved biofilm metabolic activity, except $A$. calcoaceticus cell-free supernatant (weakly inhibited biofilm activity) (Table 4).

The biofilm mass and activity results are inversely related. Similar to single species biofilms, contradictory results between biofilm mass and specific metabolic activity it was verified for all the multispecies biofilms tested, except for multispecies biofilms with $B$. cepacia cell-free supernatant (Table 4).

A comparison between multispecies biofilms with and without crude cell-free supernatants (Figure 3A and C) shows that the absence of $B$. cepacia and $A$. calcoaceticus decreased biofilm forming ability (Figure $3 \mathrm{~A})$. However, if the biofilms were formed with the cellfree supernatants of those strains (Figure 3C), there was increased biofilm productivity. On the other hand, cellfree supernatants of $S$. capsulata, M. mucogenicum and Staphylococcus sp. resulted in a slight reduction in biofilm formation compared to those without cell-free supernatants. Nonetheless, the absence of M. mucogenicum from multispecies biofilms promoted a small increase in biofilm formation. Methylobacterium sp. cell-free supernatants did not promote significant changes in multispecies biofilm formation. Regarding multispecies biofilm activity (Figure $3 \mathrm{~B}$ and D) the presence of cell-free supernatants of $S$. capsulta and Staphylococcus sp. had no significant impact on biofilm activity $(P>0.05)$. M. mucogenicum cell-free supernatant slightly improved biofilm activity. In contrast, cell-free supernatants of $B$. cepacia, Methylobacterium sp. and A. calcoaceticus caused a significant reduction in the activity of multispecies biofilms. This reduction was more pronounced for biofilms with $B$. cepacia and $A$. calcoaceticus cell-free supernatants $(P<0.05)$ and less significant for biofilms with Methylobacterium sp. $(P>0.05)$. However, only in multispecies biofilm without $A$. calcoaceticus, its cell-free supernatant caused strong inhibition of metabolic activity, compared to multispecies biofilms composed of the six bacteria $(P<0.05)$. 
Comparing the results obtained from classification of multispecies biofilms with and without cell-free supernatants (Table 4), biofilms without $S$. capsulata, Methylobacterium sp. and Staphylococcus sp. gave similar results $(P>0.05)$. These biofilms had similar biomass inhibition and metabolic activity increase whether in the presence or absence of cell-free supernatants. B. cepacia and A. calcoaceticus cell-free supernatants were important for multispecies biofilm formation, because their presence improved biofilm formation. Conversely, M. тисоgenicum cell-free supernatants inhibited multispecies biofilm formation (Table 4).

\section{Discussion}

Control of microbial growth is essential in many environments, where wet or moist surfaces provide favorable conditions for microbial proliferation and biofilm formation (Simões et al. 2009). In the industrialized world DW that is received by the consumer goes through a complex process of treatment and disinfection. However, during the distribution the quality may deteriorate and the water can become harmful to human health. The formation and presence of biofilms in DWDS have been repeatedly reported and their undesirable effects in the quality of distributed water are well known (Momba et al. 1999; Paris et al. 2009). DW biofilms are complex communities which host a wide variety of microorganisms which are well adapted to oligotrophic conditions and often grow in the presence of a disinfectant (Berry et al. 2006). These biofilms can harbour, protect and allow the proliferation of opportunistic and pathogenic bacteria. For that reason, biofilm control is crucial. However, biofilm resistance to conventional disinfection promotes the constant search for alternative control strategies. This study increases understanding of the biological mechanisms by which diverse species survive and interact in DW biofilm communities and also potentially identifies new biofilm control strategies that will ensure safer and high-quality DW. To the authors' knowledge this is the first study that investigates the effects of interspecies interactions and metabolite molecules from DW-isolated bacteria on biofilm formation/control and behaviour by these bacteria.

The bacteria used in this study are recognized as problematic opportunistic bacteria with the potential to cause public health problems (Bifulco et al. 1989; Rusin et al. 1997; Szewzyk et al. 2000; Pavlov et al. 2004; Stelma et al. 2004). Similar to other studies, single and multispecies biofilms were developed in polystyrene microtiter plates that are the most frequently used bioreactor system for studying biofilm formation, providing reliable comparative data
(Djordjevic et al. 2002; Sandberg et al. 2008; Cotter et al. 2009). Microtiter plates can be used as a rapid and simple method of screening the effects of cell-free supernatants on single and multispecies biofilm formation by DW-isolated bacteria. Polystyrene was used as a model surface. It has physico-chemical surface properties similar to those of other materials commonly used in DWDS such as stainless steel and polyvinylchloride (Simões et al. 2007a). The selected assay, based on CV staining, is a well-known method for staining biofilms produced by several Grampositive and Gram-negative bacterial strains (O'Toole and Kolter 1998; Stepanović et al. 2000; Djordjevic et al. 2002). The CV method is a simple protocol of biofilm mass staining that uses reagents that are inexpensive and easily available. This method provides reliable results, making it an attractive screening assay for small-scale laboratories (Sandberg et al. 2008). Biofilm metabolic activity was measured by the XTT staining assay. The XTT assay has been used extensively for the quantification of biofilm metabolic activity (Simões et al. 2010).

The mechanisms that control microbial interactions in multispecies biofilms are not fully understood. In the authors' previous publication on the study of biofilm interactions between DW-isolated bacteria, several types of interactions in biofilm formation were identified, viz. synergistic, antagonistic and neutral interactions (Simões et al. 2007b). However, in the present study it was not possible to elucidate the biological mechanisms involved in the relationships between these bacteria. The existence of multiple interactions or even the simple production of a metabolite can interfere (inhibit/potentiate) with the development of structurally organized biofilms (Simões et al. 2007b). Chemical substances secreted by one species of microorganism can significantly influence colonization by the other species (Rice et al. 1999; Holmström et al. 2002). To determine which factors may influence the interaction of multispecies biofilms, the DW-isolated bacteria were characterized in terms of additional key characteristics (sessile growth rates, cell-free supernatants antimicrobial activity and production of iron chelators). These characteristics and others previously reported (including planktonic growth rates, production of quorum sensing inhibitor [QSI] and quorum sensing QS molecules) (Simões et al. 2007b) are recognized as important factors regulating interspecies interactions and multispecies biofilm formation (Daniels et al. 2004; McLean et al. 2004; Banin et al. 2005; Kolmos et al. 2005; Moons et al. 2006). According to existing descriptions of multispecies biofilm population dynamics, the faster growing bacteria should outcompete those that grow more slowly (Wanner and Gujer 1986; Banks and Bryers 
1991). However, many studies have shown that slowergrowing organisms coexist with or even out-compete the faster-growing organisms in multispecies biofilms (Christensen et al. 2002; Komlos et al. 2005). The production of antimicrobial compounds, including toxins, bacteriolytic enzymes, bacteriophages, biosurfactants, antibiotics and bacteriocins seems to be a generic phenomenon for most bacteria (Riley 1998). The production of a bacteriocin could give an organism a competitive advantage when interacting with other microbes, both in gaining a foothold in a new environment and also in preventing the colonization of a potential competitor into a pre-established biofilm (Tait and Sutherland 2002). Furthermore, many bacteria are also capable of synthesizing and excreting biosurfactants with anti-adhesive properties (Desai and Banat 1997; Nitschke and Costa 2007). QS, a cell density-related communication mode between one or more species, is a significant factor adding complexity to the interactions between biofilm bacteria (Rice et al. 1999). It is also known to influence bacterial community development in aquatic biofilms (McLean et al. 2005; Dobretsov et al. 2009). QS plays a role in cell attachment and detachment from biofilms (Davies et al. 1998; Donlan 2002; Daniels et al. 2004). According to Moons et al. (2006) interference with QS may reduce the ability of biofilm bacteria to exclude competitors and, in this way, cause a shift in the natural biofilm composition. Production of iron chelators such as siderophores is a virulence factor in many microorganisms, acting as biocontrol molecules (Gram et al. 1999). Iron binding molecules have been found to have a bacteriostatic activity. Siderophores dissolve iron ions, essential to microbial survival, microbial interactions and biofilm formation, and soluble $\mathrm{Fe}^{3+}$ complexes can be taken up by active transport mechanisms (Banin et al. 2005). Antagonistic interactions were described for Bacillus cereus and Pseudomonas fluorescens in planktonic and biofilm systems due to the production of siderophores by P. fluorescens (Simões et al. 2008b).

The present study showed that Methylobacterium sp. had the highest biofilm growth rate. B. cepacia and Methylobacterium sp. produced iron chelators. None of the crude cell-free supernatants had antimicrobial activities. In a previous study (Simões et al. 2007b) $B$. cepacia had the highest planktonic growth rate and this bacterium and Methylobacterium sp. produced QSI (acyl homoserine lactones - AHLs-related molecules). These bacteria apparently had the best competitive advantage in multispecies biofilms. According to present study and based on previous work (Simões et al. 2007b), S. capsulata also showed a relatively high growth rate (planktonic and sessile), produced QSI, but not iron chelators. Staphylococcus sp. showed lower growth rates, and had the ability to produce QSI but not iron chelators. On the other hand, $A$. calcoaceticus and $M$. mucogenicum had the lowest growth rate in the planktonic and sessile state respectively, and did not have the ability to produce QSI and iron chelators. These bacteria apparently had the least competitive advantage in the biofilm consortium.

For nearly all scenarios there were contradictory results between biofilm mass and metabolic activity. The specific metabolic activity was determined to be inversely related to biofilm mass increase. Similar results were obtained in a previous study (Simões et al. 2007b). This could be explained by the fact that following microbial attachment, the formation of a complex extracellular polymeric matrix increased the non-metabolically active biofilm mass, consequently decreasing the specific respiratory activity (Simões et al. 2005). Restrictions in essential nutrients occurring in biofilms may result in a considerable decrease in bacterial metabolic activity (Wentland et al. 1996; Walker et al. 1998; Stewart and Franklin 2008).

The assessment of the effects of metabolite molecules on single species biofilms led to the identification of four biofilms (A. calcoaceticus, B. cepacia, Methylobacterium sp. and $M$. mucogenicum) which were inhibited and two biofilms which were improved $(S$. capsulata and Staphylococcus sp.) by the metabolite molecules produced by the partner DW-isolated bacteria. This suggests that all bacterial metabolite molecules had potential biocontrol properties in four of the six single species biofilms. M. mucogenicum and B. cepacia biofilms were strongly inhibited by all cellfree supernatants. These biofilms are the most susceptible to metabolites produced by different bacteria. On the other hand, A. calcoaceticus biofilms were the least affected. The bacteria that produced metabolite molecules more inhibitory to single species biofilm formation were $S$. capsulata (on $M$. mucogenicum and A. calcoaceticus biofilms) and M. mucogenicum (on $B$. cepacia and Methylobacterium sp. biofilms). S. capsulata biofilm formation was strongly enhanced by the presence of all cell-free supernatants (Staphylococcus sp. cell-free supernatant promoted the most significant increase in biofilm formation). For Staphylococcus biofilms, the cell-free supernatant which most increased biofilm formation was that from Methylobacterium $\mathrm{sp}$.

According to some authors (Rice et al. 1999; Shank and Kolter 2009), many microorganisms can grow better in combination with others or in the presence of a partner's diffusible compounds. Several species can coexist in biofilms where the behavior is the sum of synergistic and antagonistic interactions, as they can produce metabolites that can interfere negatively or 
positively with growth and biofilm formation (Simões et al. 2008b). Biofilms in DWDS are constituted of several different bacterial species, so it is important to understand the role of each species and/or their metabolite molecules in the community. The present results show that all the bacteria, except $M$. mucogenicum, had an important role in the development of multispecies biofilms, because their absence caused a reduction in biofilm formation. The absence of $A$. calcoaceticus caused the highest reduction. Concerning the effects of metabolite molecules produced by DWisolated bacteria on multispecies biofilms, the presence of cell-free supernatants of $A$. calcoaceticus and $B$. cepacia increased biofilm formation. On the other hand, the presence of $S$. capsulata, M. mucogenicum, Methylobacterium sp. and Staphylococcus sp. cell-free supernatants decreased multispecies biofilm formation (compared with the control experiment, ie biofilms with all the bacteria). For the comparison of multispecies biofilms with and without crude cell-free supernatants, $S$. capsulata, $M$. mucogenicum and Staphylococcus sp. cell-free supernatants led only to a slight reduction in multispecies biofilm formation. The metabolite molecules produced by these bacteria had biocontrol properties. The cell-free supernatant of $M$. mucogenicum promoted the most significant biocontrol potential. The presence of Methylobacterium sp. cell-free supernatant had no significant effects on multispecies biofilm formation. The metabolite molecules produced by this bacterium were not apparently important to the biofilm community. On the other hand, metabolite molecules of $A$. calcoaceticus and $B$. cepacia had a significant role in multispecies biofilm community; their presence significantly improved biofilm formation.

A. calcoaceticus had the lowest planktonic growth rate (Simões et al. 2007b), had one of the lowest biofilm growth rates, and was a non-producer of QSI and iron chelators. However, this bacterium formed single species biofilms which were the least susceptible to microbial metabolites produced by the other DWisolated bacteria and showed important features in the multispecies biofilm consortium. In these biofilms, the absence of $A$. calcoaceticus caused the most significant reduction in biofilm formation. This effect could be due to the importance of this bacterium in coaggregation. In previous work Simões et al. (2008a) reported that $A$. calcoaceticus coaggregated with almost all the other bacteria, and its presence in a multispecies community represented a colonization advantage, suggesting that this species may facilitate the association of the other species that do not coaggregate directly with each other, increasing the opportunity for metabolic cooperation. Min et al. (2010) also reported that coaggregation enhanced biofilm development between freshwater bacteria. On the other hand, the metabolite molecules produced by $A$. calcoaceticus significantly improved multispecies biofilm formation, possibly due to the production of extracellular proteins and polysaccharides involved in coaggregation. The absence of $B$. cepacia in multispecies biofilms also caused a significant mass reduction in the biofilm, but the presence of its metabolite molecules improved significantly multispecies biofilm formation. This fact could be related with the ability of this bacterium to produce QSI (Simões et al. 2007b) and iron chelators.

For M. mucogenicum QSI and iron chelator production were not detected (Simões et al. 2007b). This bacterium had a low growth rate (Simões et al. 2007b), and formed single species biofilms which were the most affected by the molecules produced by the other DW bacteria. In multispecies biofilms, its absence improved biofilm formation, but its metabolites caused the most significant biocontrol potential. In previous work (Simões et al. 2007b), it was reported that M. mucogenicum established only antagonistic (with $S$. capsulata and with Staphylococcus sp.) or neutral (with A. calcoaceticus and with Methylobacterium sp.) interactions with DW-isolated bacteria. Qin et al. (2009) also observed that extracellular products produced by Pseudomonas aeruginosa inhibited the growth of Staphylococcus epidermidis and disrupted its established biofilms. Tait and Sutherland (2002), using a batch system for biofilm formation, found that a bacteriocin-producing strain more easily gained a foothold in an existing biofilm of bacteriocin-sensitive bacteria than vice versa. Rao et al. (2005) studied dualspecies biofilms formed in a continuous flow chamber with Pseudoalteromonas tunicata, a marine bacterium that produces the antibacterial protein AlpP, and found that the organism could completely outgrow competitor bacteria that were sensitive to this protein, but not those that were only moderately sensitive or those that themselves produced an antimicrobial compound to which $P$. tunicata was sensitive. A Serratia plymuthica strain produced an antimicrobial component with the ability to inhibit biofilm formation by Escherichia coli and mixed biofilms of E. coli and $S$. plymuthica (Moons et al. 2006). These examples illustrate the important role of antimicrobial compound production in shaping mixed-species biofilms.

The reduction in multispecies biofilm formation caused by the absence of Methylobacterium sp. did not appear to be related to the metabolite molecules produced by this bacterium, despite the fact that QSI, AHL and iron chelators were detected. The mass of multispecies biofilms with and without crude cell-free supernatants of Methylobacterium sp. was similar, which could be explained by a high biofilm growth rate and the ability to produce biofilms with high cell densities (Simões et al. 2010). 
In conclusion, this study has led to a better understanding of the role of bacterial interactions and metabolites produced by DW-isolated bacteria in biofilm formation and development in single and multispecies biofilms. The identification of bacterial species which have biocontrol potential (M. mucogenicum) or have a significant role in development and maintenance of the DW consortium (A. calcoaceticus and $B$. cepacia), provide new insights for improving the successful control of biofilms in DWDS.

\section{Acknowledgement}

The authors acknowledge the financial support provided by the Portuguese Foundation for Science and Technology (SFRH/BD/31661/2006 - Lúcia C. Simões).

\section{References}

Amblard C, Bourdier G, Carrias JF, Maurin N, Quiblier C. 1996. Seasonal evolution of the structure of microbial community in a drinking water tank. Water Res 30: 613-624.

Ammor S, Tauveron G, Dufour E, Chevalier I. 2006. Antibacterial activity of lactic acid bacteria against spoilage and pathogenic bacteria isolated from the same meat small-scale facility 1 - screening and characterization of the antibacterial compounds. Food Control 17:454-461.

Andersson MA, Mikkola R, Helin J, Andersson MC, Salkinoja-Salonen M. 1998. A novel sensitive bioassay for detection of Bacillus cereus emetic toxin and related depsipeptide ionophores. Appl Environ Microbiol 64: 1338-1343.

Banin E, Vasil ML, Greenberg PE. 2005. Iron and Pseudomonas aeruginosa biofilm formation. Proc Natl Acad Sci USA 102:11076-11081.

Banks MK, Bryers JD. 1991. Bacterial species dominance within a binary culture biofilm. Appl Environ Microbiol 57:1974-1979.

Berry D, Xi C, Raskin L. 2006. Microbial ecology of drinking water distribution systems. Curr Opin Biotechnol 17: 297-302.

Bifulco JM, James T, Shirey J, Bissonnette GK. 1989. Detection of Acinetobacter spp. in rural drinking water supplies. Appl Environ Microbiol 55:2214-2219.

Block JC, Sibille I, Gatel D, Reasoner DJ, Lykins B, Clark RM. 1997. Biodiversity in drinking water distribution systems: a brief review. In: Jones JG, Sutcliffe D, editors. The microbiological quality of water. London (UK): Royal Soc Public Hlth Hyg Publishers. p. 63-71.

Bryers JD, Ratner BD. 2004. Bioinspired implant materials befuddle bacteria. ASM News 70:232-237.

Christensen BB, Haagensen JA, Heydorn A, Molin S. 2002. Metabolic commensalism and competition in a twospecies microbial consortium. Appl Environ Microbiol 68:2495-2502.

Chorianopoulos NG, Giaouris ED, Kourkoutas Y, Nychas G-JE. 2010. Inhibition of the early stage of Salmonella enterica serovar enteritidis biofilm development on stainless steel by cell-free supernatant of a Hafnia alvei culture. Appl Environ Microbiol 76:2018-2022.
Costerton JW, Stewart PS, Greenberg EP. 1999. Bacterial biofilms: a common cause of persistent infections. Science 284:1318-1322.

Cotter JJ, O'Gara JP, Casey E. 2009. Rapid deplection of dissolved oxygen in 96-well microtiter plate Staphylococcus epidermidis biofilm assays promotes biofilm development and is influenced by inoculum cell concentration. Biotechnol Bioeng 103:1042-1047.

Daniels R, Vanderleyden J, Michiels J. 2004. Quorum sensing and swarming migration in bacteria. FEMS Microbiol Rev 28:261-289.

Davies DG, Parsek MR, Pearson JP, Iglewski BH, Costerton JW, Greenberg EP. 1998. The involvement of cell-to-cell signals in the development of a bacterial biofilm. Science 280:295-298.

Desai JD, Banat IM. 1997. Microbial production of surfactants and their commercial potential. Microbiol Mol Biol Rev 61:47-64.

Djordjevic D, Wiedmann M, McLandsborough LA. 2002. Microtiter plate assay for assessment of Listeria monocytogenes biofilm formation. Appl Environ Microbiol 68:2950-2958.

Dobretsov S, Teplitski M, Valerie P. 2009. Mini-review: quorum sensing in the marine environment and its relationship to biofouling. Biofouling 25: 413-427.

Donlan RM. 2002. Biofilms: microbial life on surfaces. Emerg Infect Dis 8:881-890.

Elenter D, Milferstedt K, Zhang W, Hausner M, Morgenroth E. 2007. Influence of detachment on substrate removal and microbial ecology in a heterotrophic/ autotrophic biofilm. Water Res 41:4657-4671.

Ferreira C, Rosmaninho R, Simões M, Pereira MC, Bastos MMSM, Nunes OC, Coelho M, Melo LF. 2010. Biofouling control using microparticles carrying a biocide. Biofouling 26:205-212.

Gilbert P, Allison DG, McBain AJ. 2002. Biofilms in vitro and in vivo: do singular mechanisms imply crossresistance? J Appl Microbiol 92:98S-110S.

Gram L, Melchiorsen J, Spanggaard B, Huber I, Nielsen TF. 1999. Inhibition of Vibrio anguillarum by Pseudomonas fluorescens $\mathrm{AH} 2$, a possible probiotic treatment of fish. Appl Environ Microbiol 65:969-973.

Hansen SK, Rainey PB, Haagensen JAJ, Molin S. 2007. Evolution of species interactions in a biofilm community. Nature 445:533-536.

Holmström C, Egan S, Franks A, McCloy S, Kjelleberg S. 2002. Antifouling activities expressed by marine surface associated Pseudoalteromonas species. FEMS Microbiol Ecol 41:47-58.

Hughes KA, Sutherland IW, Jones MV. 1998. Biofilm susceptibility to bacteriophage attack: the role of phage-borne polysaccharide depolymerase. Microbiology 144:3039-3047.

Irie Y, Parsek MR. 2008. Quorum sensing and microbial biofilms. Curr Top Microbiol Immunol 322:67-84.

Kolari M, Nuutinen J, Salkinoja-Salonen MS. 2001. Mechanisms of biofilm formation in paper machine by Bacillus species: the role of Deinococcus geothermalis. J Ind Microbiol Biotechnol 27:343-351.

Komlos J, Cunningham AB, Camper AK, Sharp RR. 2005. Interaction of Klebsiella oxytoca and Burkholderia cepacia in dual-species batch cultures and biofilms as a function of growth rate and substrate concentration. Microb Ecol 49:114-125. 
Lequette Y, Boels G, Clarisse M; Faille C. 2010. Using enzymes to remove biofilms of bacterial isolates sampled in the food-industry. Biofouling 26:421-431.

Leroy C, Delbarre C, Ghillebaert F, Compere C, Combes D. 2008. Effects of commercial enzymes on the adhesion of a marine biofilm-forming bacterium. Biofouling 24:11-22.

Manuel CM, Nunes OC, Melo LF. 2009. Unsteady state flow and stagnation in distribution systems affect the biological stability of drinking water. Biofouling 26:129-139.

McLean RJC, Pierson III LS, Fuqua C. 2004. A simple screening protocol for the identification of quorum signal antagonists. J Microbiol Methods 58:351-360.

McLean RJC, Barnes MB, Windham MK, Merchant M, Forstner MRJ, Fuqua C. 2005. Cell-cell influences on bacterial community development in aquatic biofilms. Appl Environ Microbiol 71:8987-8990.

Messi P, Anacarso I, Bargellini A, Bondi M, Marshesi I, de Niederhäusern S, Borella P. 2011. Ecological behaviour of three serogroups of Legionella pneumophila within a model plumbing system. Biofouling 27:165-172.

Meyer B. 2003. Approaches to prevention, removal and killing of biofilms. Int Biodeterior Biodegrad 51: 249-253.

Min KR, Zimmer MN, Rickard AH. 2010. Physicochemical parameters influencing coaggregation between the freshwater bacteria Sphingomonas natatoria 2.1 and Micrococcus luteus 2.13. Biofouling 26:931-940.

Mireles JR, Toguchi A, Harshey RM. 2001. Salmonella enterica serovar Typhimurium swarming mutants with altered biofilm-forming abilities: surfactin inhibits biofilm formation. J Bacteriol 183:5848-5854.

Momba MNB, Cloete TE, Venter SN, Kfir R. 1999. Examination of the behaviour of Escherichia coli in biofilms established in laboratory-scale units receiving chlorinated and chloraminated water. Water Res 33:2937-2940.

Moons P, Van Houdt R, Aertsen A, Vanoirbeek K, Engelborghs Y, Michiels CW. 2006. Role of quorum sensing and antimicrobial component production by Serratia plymuthica in formation of biofilms including mixed biofilms with Escherichia coli. Appl Environ Microbiol 72:7294-7300.

Nitschke M, Costa SGVAO. 2007. Biosurfactants in food industry. Trends Food Sci Technol 18:252-259.

Olsen SM, Pedersen LT, Laursen MH, Kiil S, Dam-Johansen K. 2007. Enzyme-based antifouling coatings: a review. Biofouling 23:369-383.

O'Toole G, Kolter R. 1998. Flagellar and twitching motility are necessary for Pseudomonas aeruginosa biofilm development. Mol Microbiol 30:295-304.

Paris T, Skali-Lami S, Block J-C. 2009. Probing young drinking water biofilms with hard and soft particles. Water Res 43:117-126.

Pavlov D, de Wet CM, Grabow WO, Ehlers MM. 2004. Potentially pathogenic features of heterotrophic plate count bacteria isolated from treated and untreated drinking water. Int J Food Microbiol 92:275-287.

Percival SL, Walker JT. 1999. Potable water and biofilms: a review of the public health implications. Biofouling 42:99-115.

Qin Z, Yang L, Qu D, Molin S, Tolker-Nielsen T. 2009. Pseudomonas aeruginosa extracellular products inhibit staphylococcal growth, and disrupt established biofilms produced by Staphylococcus epidermidis. Microbiology 155:2148-2156.
Rao D, Webb JS, Kjelleberg S. 2005. Competitive interactions in mixed-species biofilms containing the marine bacterium Pseudoalteromonas tunicata. Appl Environ Microbiol 71:1729-1736.

Rasmussen TB, Skindersoe ME, Bjarnsholt T, Phipps RK, Christensen KB, Jensen PO, Anderson JB, Koch B, Larsen TO, Hentzer M, et al. 2005. Identity and effects of quorum-sensing inhibitors produced by Penicilium species. Microbiology 151:1325-1340.

Reasoner DJ, Geldrich EE. 1985. A new medium for the enumeration and subculture of bacteria from potable water. Appl Environ Microbiol 49:1-7.

Rice SA, Givskov M, Steinberg P, Kjelleberg S. 1999. Bacterial signals and antagonists: the interaction between bacteria and higher organisms. J Mol Microbiol Biotechnol 1:23-31.

Riley MA. 1998. Molecular mechanism of bacteriocin evolution. Annu Rev Genet 32:255-278.

Rusin PA, Rose JB, Haas CN, Gerba CP. 1997. Risk assessment of opportunistic bacterial pathogens in drinking water. Rev Environ Contam Toxicol 152:57-83.

Sandberg M, Määttänen A, Peltonen J, Vuorela PM, Fallarero A. 2008. Automating a 96-well microtiter plate model for Staphylococcus aureus biofilms: an approach to screening of natural antimicrobial compounds. Int $\mathbf{J}$ Antimicrob Agents 32:233-240.

Schwyn B, Neilands JB. 1987. Universal chemical assay for the detection and determination of siderophores. Anal Biochem 160:47-56.

Sillankorva S, Neubauer P, Azeredo J. 2010. Phage control of dual species biofilms of Pseudomonas fluorescens and Staphylococcus lentus. Biofouling 26:567-575.

Sillankorva S, Oliveira DR, Vieira MJ, Sutherland IW, Azeredo J. 2004. Bacteriophage ФS1 infection of Pseudomonas fluorescens planktonic cells versus biofilms. Biofouling 20:133-138.

Shank EA, Kolter R. 2009. New developments in microbial interspecies signaling. Curr Opin Microbiol 12:205-214.

Simões LC, Simões M, Vieira MJ. 2007b. Biofilm interactions between distinct bacterial genera isolated from drinking water. Appl Environ Microbiol 73:6192-6200.

Simões LC, Simões M, Vieira MJ. 2007c. Microbial interactions in drinking water biofilms. In: Gilbert P, Allison D, Brading M, Pratten J, Spratt D, Upton M, Biofilms: coming of age. Manchester (UK): The Biofilm Club. p. 43-52.

Simões LC, Simões M, Vieira MJ. 2008a. Intergeneric coaggregation among drinking water bacteria: evidence of a role for Acinetobacter calcoaceticusas a bridging bacterium. Appl Environ Microbiol 74:1259-1263.

Simões LC, Simões M, Vieira MJ. 2010. Influence of the diversity of bacterial isolates from drinking water on resistance of biofilms to disinfection. Appl Environ Microbiol 76:6673-6679.

Simões LC, Simões M, Oliveira R, Vieira MJ. 2007a. Potential of the adhesion of bacteria isolated from drinking water to materials. J Basic Microbiol 47: 174-183.

Simões LC, Azevedo N, Pacheco A, Keevil CW, Vieira MJ. 2006. Drinking water biofilm assessment of total and culturable bacteria under different operating conditions. Biofouling 22:91-99.

Simões LC, Lemos M, Araújo P, Pereira AM, Simões M. 2011. The effects of glutaraldehyde on the control of single and dual biofilms of Bacillus cereus and Pseudomonas fluorescens. Biofouling 27:337-346. 
Simões M, Pereira MO, Vieira MJ. 2005. Action of a cationic surfactant on the activity and removal of bacterial biofilms formed under different flow regimes. Water Res 39:478-486.

Simões M, Simões LC, Vieira MJ. 2009. Species association increases biofilm resistance to chemical and mechanical treatments. Water Res 43:229-237.

Simões M, Simões LC, Pereira MO, Vieira MJ. 2008 b. Antagonism between Bacillus cereus and Pseudomonas fluorescens in planktonic systems and in biofilms. Biofouling 24:339-349.

Singh PK, Parsek MR, Greenberg PE, Welsh MJ. 2002. A component of innate immunity prevents bacterial biofilm development. Nature 417:552-555.

Stelma Jr GN, Lye DJ, Smith BG, Messer JW, Payment P. 2004. Rare occurrence of heterotrophic bacteria with pathogenic potential in potable water. Int $\mathbf{J}$ Food Microbiol 92:249-254.

Stepanović S, Vuković D, Davić I, Savić B, Ŝvabić-Vlahović M. 2000. A modified microtiter-plate test for quantification of staphylococcal biofilm formation. J Microbiol Methods 40:175-179.

Stewart PS, Franklin MJ. 2008. Physiological heterogeneity in biofilms. Nat Rev Microbiol 6:199-210.
Szewzyk U, Szewzyk R, Manz W, Schleifer K-H.. 2000. Microbiological safety of drinking water. Annu Rev Microbiol 54:81-127.

Tait K, Sutherland IW. 2002. Antagonistic interactions amongst bacteriocin-producing enteric bacteria in dual species biofilms. J Appl Microbiol 93:345-352.

Tait K, Skillman LC, Sutherland IW. 2002. The efficacy of bacteriophage as a method of biofilm eradication. Biofouling 18:305-311.

Van Houdt R, Aertsen A, Jansen A, Quintana AL, Michiels CW. 2004. Biofilm formation and cell-to-cell signalling in Gram-negative bacteria isolated from a food processing environment. J Appl Microbiol 96:177-184.

Walker SL, Brocklehurst TF, Wimpenny JWT. 1998. Adenylates and adenylate-energy charge in submerged and planktonic cultures of Salmonella enteritidis and Salmonella typhimurium. Int J Food Microbiol 44: 107-113.

Wanner O, Gujer W. 1986. A multispecies biofilm model. Biotechnol Bioeng 28:314-328.

Wentland EJ, Stewart PS, Huang CT, McFeters GA. 1996. Spational variations in growth rate within Klebsiella pneumonia colonies and biofilm. Biotechnol Prog 12: 316-321. 